University of Tennessee Health Science Center

UTHSC Digital Commons

\title{
Glycan Shielding of the Influenza Virus Hemagglutinin Elicits Evasion of the Adaptive Immune Response and T-Cell-Driven Pathology
}

Keith C. Wanzeck

University of Tennessee Health Science Center

Follow this and additional works at: https://dc.uthsc.edu/dissertations

Part of the Influenza Humans Commons, Medical Molecular Biology Commons, and the Virus Diseases Commons

\section{Recommended Citation}

Wanzeck, Keith C. , "Glycan Shielding of the Influenza Virus Hemagglutinin Elicits Evasion of the Adaptive Immune Response and T-Cell-Driven Pathology" (2010). Theses and Dissertations (ETD). Paper 280. http://dx.doi.org/10.21007/etd.cghs.2010.0344. 


\title{
Glycan Shielding of the Influenza Virus Hemagglutinin Elicits Evasion of the Adaptive Immune Response and T-Cell-Driven Pathology
}

\author{
Abstract \\ Three separate influenza pandemics have emerged in the human population since 1918, each \\ characterized by viruses that lack $\mathrm{N}$-linked glycosylation sites on the globular head of the hemagglutinin \\ protein. In contrast, recent non-pandemic isolates have acquired such sites. Here we constructed \\ isogenic viruses containing differing numbers of additional N-linked glycosylation sites to assess the \\ impact on the host immune response. These studies show that mice infected with a glycosylated virus \\ remain susceptible to challenge with a non-glycosylated virus, glycosylated viruses elicit an inferior \\ immune response, and in this context T-cell pathology and death may occur. We conclude from these data \\ that glycosylation leads to a lack of neutralization coupled with a robust T-cell response. Specifically, \\ glycosylation of HA seems to shield neutralizing antibody epitopes while leaving T-cell epitopes \\ unaffected. These results may be particularly significant in the context of the recent influenza pandemic.

\section{Document Type} \\ Thesis

\section{Degree Name} \\ Master of Science (MS)

\section{Program} \\ Biomedical Sciences \\ Research Advisor \\ Jonathan A. McCullers Ph.D.

\section{Keywords} \\ glycosylation, hemagglutinin, influenza, neutralizing antibodies, T-cells

\section{Subject Categories} \\ Diseases | Influenza Humans | Medical Molecular Biology | Medical Sciences | Medicine and Health \\ Sciences | Virus Diseases
}




\title{
Glycan Shielding of the Influenza Virus Hemagglutinin Elicits Evasion of the
} Adaptive Immune Response and T-Cell-Driven Pathology

\author{
A Thesis \\ Presented for \\ The Graduate Studies Council \\ The University of Tennessee \\ Health Science Center
}

In Partial Fulfillment

Of the Requirements for the Degree

Master of Science

From The University of Tennessee

Keith C. Wanzeck

May 2010 
Copyright@ @2010 by Keith C. Wanzeck

All rights reserved 


\begin{abstract}
Three separate influenza pandemics have emerged in the human population since 1918 , each characterized by viruses that lack N-linked glycosylation sites on the globular head of the hemagglutinin protein. In contrast, recent non-pandemic isolates have acquired such sites. Here we constructed isogenic viruses containing differing numbers of additional N-linked glycosylation sites to assess the impact on the host immune response. These studies show that mice infected with a glycosylated virus remain susceptible to challenge with a non-glycosylated virus, glycosylated viruses elicit an inferior immune response, and in this context T-cell pathology and death may occur. We conclude from these data that glycosylation leads to a lack of neutralization coupled with a robust T-cell response. Specifically, glycosylation of HA seems to shield neutralizing antibody epitopes while leaving T-cell epitopes unaffected. These results may be particularly significant in the context of the recent influenza pandemic.
\end{abstract}




\section{Table of Contents}

Chapter 1: Introduction ..........................................................................................

Chapter 2: Materials and Methods .........................................................................6

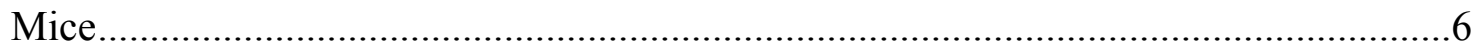

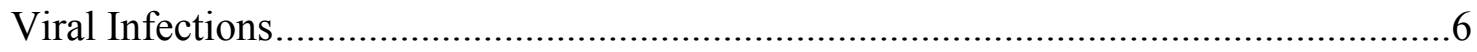

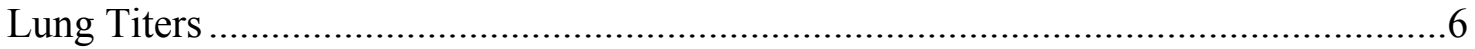

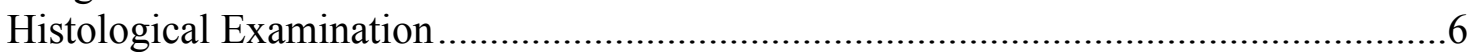

Serum Collection and Treatment............................................................................ 7

Immune Assays ..................................................................................................

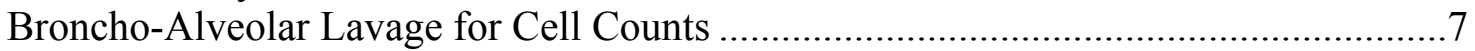

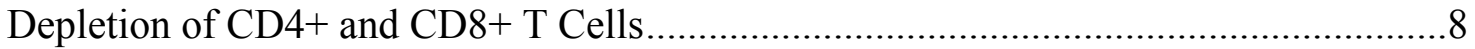

Chapter 3: Infection of Mice with a Highly Glycosylated Influenza Virus Followed by Challenge with a Virus Exhibiting Less Glycosylation Can Lead to Death..................9

Chapter 4: Protection in This Model Is Antibody Mediated...........................................13

Chapter 5: Increasing Glycosylation Leads to a Decreased Antibody Response .............16

Chapter 6: T-Cell Responses after Virus Challenge ......................................................18

T-Cell Response in This Model Can Be Both Harmful and Protective .........................18

Highly Glycosylated Virus Leads to More Lung Pathology and Greater T-Cell Influx upon Challenge with WT ................................................................................ 18

Chapter 7: Effect of Infection with a Heavily Glycosylated Virus on Delayed

Challenge with a Virus Exhibiting Less Glycosylation...

Delayed WT Challenge Has No Effect on Pathology in +4 Infected Mice but Abolishes Protection Seen in +2 Infected Mice .24

WT Virus Elicits an Improved Immune Response Compared to +4 Virus at the Day 120 Time Point

Chapter 8: Mice Suffer Pathology When Infected with a Seasonal H1N1 Isolate and Then Challenged with the S-OIV Swine Influenza, a Virus Exhibiting Less Glycosylation .27

Chapter 9: Impact of Results on Scientific Understanding and Future Goals .................29

Glycosylation and the Evolution of Influenza Virus..............................................29

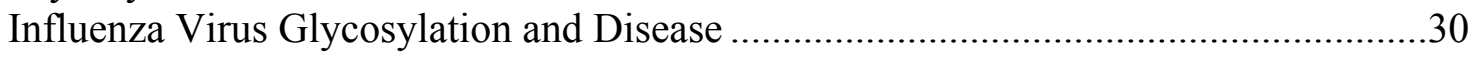

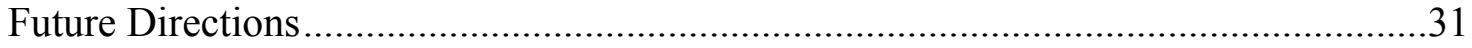

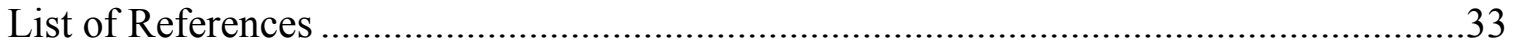

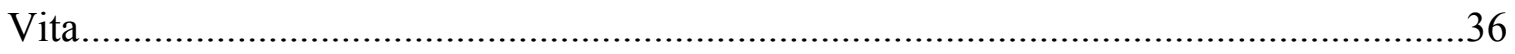




\section{List of Figures}

Figure 1. Mice infected with a highly glycosylated virus and re-infected with a virus exhibiting less glycosylation suffer weight loss.

Figure 2. Mice infected with a highly glycosylated virus and re-infected with a virus exhibiting less glycosylation succumb.

Figure 3. Regardless of initial infection, mice clear challenge virus from lungs by day 3.

Figure 4. Protection conferred by +2 and WT viral infection against weight loss is antibody mediated

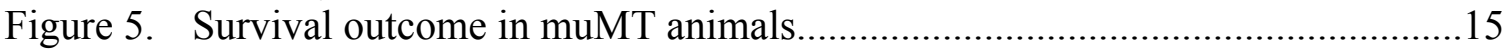

Figure 6. +4 infected mice elicit lower antibody response than +2 and WT infected mice when assessed with WT as the target virus ..........................................17

Figure 7. Depletion of T cells upon WT challenge abolishes weight loss and death......19

Figure 8. +4 infected mice show the greatest degree of lung damage 3 days post WT challenge .20

Figure 9. +4 infected mice show the greatest amount of T-cell influx 3 days post WT challenge

Figure 10. +4 infected mice show the greatest amount of T-cell infiltrate in the lungs ...23

Figure 11. Delayed WT challenge has no effect on pathology seen in +4 infected mice but leads to a loss of protection in the case of +2 infected mice

Figure 12. WT virus elicits an improved immune response compared to +4 virus at the day 120 time point

Figure 13. Mice suffer pathology when infected with a seasonal H1N1 isolate and then challenged with S-OIV. 


\section{List of Abbreviations}

+2 Isogenic influenza virus stock with 2 n-linked glycosylation sites on the globular head

+4 Isogenic influenza virus stock with 4 n-linked glycosylation sites on the globular head

BAL Bronchoalveolar lavage

ELISA Enzyme-linked immunosorbant assay

HA Hemagglutinin

HAI Hemagglutination inhibition

Ig Immunoglobulin

muMT Mice lacking B cells

NA Neuraminidase

OAS Original antigenic $\sin$

RDE Receptor-destroying enzyme

S-OIV H1N1 swine-origin virus

SP-D Surfactant protein D

TCID Tissue culture infectious dose

WT Isogenic influenza virus stock with 0 n-linked glycosylation sites on the globular head (HA from 1968 H3N2 Hong Kong) 


\section{Chapter 1: Introduction}

Influenza viruses are part of the Orthomyxoviridae family, which consists of influenza A, B, and C viruses, Isavirus, and Thogotovirus. This family consists of viruses that have a negative-sense, single-stranded, and segmented RNA genome. Influenza A viruses are classified by hemagglutinin (HA) and neuraminidase (NA) subtype. Currently there are 16 different HA subtypes (H1 to H16) and 9 different NA subtypes (N1 to N9). The influenza A virus genome consists of 8 segments that encode for 11 proteins. The two proteins used for viral subtyping, the HA and NA surface glycoproteins, are found anchored in the envelope of the virus. The HA protein is responsible for receptor binding and fusion of the virus. The HA protein is important also as the major antigenic protein of influenza A viruses. The NA protein is responsible for viral cleavage from host receptors allowing for viral release. The HA, NA, and matrix protein 2 (M2) are the external proteins of influenza A viruses. The internal proteins consist of matrix protein 1 (M1), polymerase basic 1 and 2 (PB1 and PB2), polymerase acid (PA), nucleoprotein (NP), non-structural proteins 1 and 2 (NS1 and NS2), and PB1-F2 an alternate reading frame protein from PB1 [1].

Upon initial infection, influenza viruses gain entry to the host cell through the HA protein binding to sialic acid residues present on cell surface glycoproteins. Different influenza viruses can have different specificities for different sialic acid linkages. Viruses then enter the cell by receptor-mediated endocytosis, the virus is then uncoated to allow for fusion of the HA membrane with the cellular membrane based on a low $\mathrm{pH}-$ induced conformational change of the HA molecule [1;2]. Viral RNPs then make their way into the nucleus to replicate using cellular machinery. The newly produced RNPs are then transported to the cytoplasm for assembly [3]. After packaging of the complete genome, the newly formed viral membrane again fuses with the cellular membrane initiating budding and release [1]. The NA protein can then cleave the viral particle from the cell membrane allowing for viral release.

One important aspect of influenza is the ability of the virus to rapidly mutate to create antigenically distinct strains [4]. This can occur through two distinct mechanisms, drift and shift. Drift is the natural accumulation of mutations due to the lack of a proofreading mechanism found in RNA polymerase. In the case of influenza HA, many of the mutations occur in antigenic regions, leading to mostly similar strains of virus that are none-the-less antigenically distinct. On the other hand, shift occurs due to the reaasortment of genes from different viruses, usually swapping a surface antigen from one virus to another, creating a novel virus. Antigenic shift is thought to be the cause of the majority of influenza pandemics.

One common alteration is the acquisition of additional n-linked glycosylation sites in and around the HA globular head. Glycosylation is a common post-translational modification made to many proteins. There are two types of glycosylation, $n$-linked and o-linked. Both the HA and NA proteins carry sites for potential n-linked glycosylation, where oligosaccharide chains are attached to the asparagine residues of the consensus n- 
linked glycosylation sequence, Asn-X-Ser/Thr, where $\mathrm{X}$ can be any amino acid but proline. As the HA protein mutates frequently, there is much potential for it to acquire this consensus sequence $[5 ; 6]$.

Since 1918, there have been three human influenza A pandemics (1918 H1N1 Spanish, 1957 H2N2 Asian and 1968 H3N2 Hong Kong). Combined, these pandemics have caused million of deaths worldwide. In each case, the acquisition of a novel hemagglutinin (HA) glycoprotein was the prevailing factor that led to pandemic status, as the HA protein is the primary target of neutralization by the immune system. As each of these pandemics, from different subtypes, has been introduced to the human population they have shared one common trait, the lack of glycosylation sites on the globular head of the HA protein. In the case of each of these subtypes, as the viruses evolved in the human population they started to acquire these sites. Table 1 shows the acquisition of these sites for the H3N2 subtype. In 1968 when this subtype entered the human population it possessed 6 potential glycosylation sites, eventually acquiring 11 sites by 2002. This pattern is also seen in the $\mathrm{H} 1 \mathrm{~N} 1$ and $\mathrm{H} 2 \mathrm{~N} 2$ subtypes. Alternatively, influenza $B$ viruses also have the ability to acquire these sites, but do not show this same pattern of progressive additions (Table 2).

The significance of glycosylation on the globular head of influenza HA is poorly understood. Studies have shown that while glycosylation can affect receptor binding activity, cell fusion and intracellular transport are not affected (2). Studies have also shown that addition of a glycosylation site can allow viral escape from a monoclonal antibody [7]. Thus glycosylation can change viral antigenicity without deficits in biological activity $[7 ; 8]$. As previous studies in our lab have shown, increased glycosylation of an $\mathrm{H} 3 \mathrm{~N} 2$ virus leads to decreased virulence, at least partially the result of more efficient clearance of the virus by surfactant protein D (SP-D), an important part of the innate defense against influenza [9]. SP-D activity was shown to be dependent on specific glycosylation sites; increased clearance by SP-D was also shown to be relevant in other influenza subtypes [10]. On the other hand, the loss of a glycosylation site leads to increased virulence and resistance to murine collectins [11]. Thus the addition of glycosylation to the HA leads to improved clearance by the innate immune system and decreased virulence. This led us to question if there was a tradeoff between enhanced evasion of adaptive immune responses at the expense of enhanced clearance by innate immune responses, specifically by SP-D.

It has been postulated previously that the function of glycosylation on the globular head of the HA protein is to shield antigenic sites. We therefore questioned what the effect of infection with highly glycosylated virus would have on the adaptive immune system when compared to infection with a less glycosylated virus. To investigate the consequence on the adaptive immune response of successive exposures to glycosylated and then non-glycosylated viruses, we designed a murine model system. HK68 2:6 mutants (viruses containing HA and Neuraminidase (NA) genes from HK68 and internal genes from mouse adapted PR8) created previously [9] were used to sequentially infect mice. This allowed us to access the impact of glycosylation status on disease progression, antibody response, and T-cell response. 
Table 1. Evolutionary acquisition of glycosylation in $\mathrm{H} 3 \mathrm{~N} 2$ viruses

\begin{tabular}{|c|c|c|}
\hline Virus & $\begin{array}{c}\text { Potential Glycosylation } \\
\text { Sites }\end{array}$ & $\begin{array}{c}\text { Number of } \\
\text { Potential Sites }\end{array}$ \\
\hline A/Hong Kong/1/68 & $\mathbf{8}, \mathbf{2 2}, \mathbf{3 8}, 81,165, \mathbf{2 8 5}$ & 6 \\
\hline A/Port Chalmers/1/73 & $\mathbf{8}, \mathbf{2 2}, \mathbf{3 8}, 63,81,165, \mathbf{2 8 5}$ & 7 \\
\hline A/Victoria/3/75 & $\mathbf{8},(9), \mathbf{2 2}, \mathbf{3 8}, 63,126,165, \mathbf{2 8 5}$ & $7(8)$ \\
\hline $\mathrm{A} / \mathrm{Texas} / 1 / 77$ & $\mathbf{8}, \mathbf{2 2}, \mathbf{3 8}, 63,126,165, \mathbf{2 8 5}$ & 7 \\
\hline A/Leningrad/360/86 & $\mathbf{8}, \mathbf{2 2}, \mathbf{3 8}, 63,126,165,246, \mathbf{2 8 5}$ & 8 \\
\hline A/Memphis/6/86 & $\mathbf{8}, \mathbf{2 2}, \mathbf{3 8}, 63,126,165,246, \mathbf{2 8 5}$ & 8 \\
\hline A/Memphis/8/88 & $\mathbf{8}, \mathbf{2 2}, \mathbf{3 8}, 63,126,165,246, \mathbf{2 8 5}$ & 8 \\
\hline A/Beijing/385/89 & $\mathbf{8}, \mathbf{2 2}, \mathbf{3 8}, 63,126,165,246, \mathbf{2 8 5}$ & 8 \\
\hline A/Memphis/7/90 & $\mathbf{8}, \mathbf{2 2}, \mathbf{3 8}, 63,126,165,246, \mathbf{2 8 5}$ & 8 \\
\hline A/Beijing/32/92 & $\mathbf{8}, \mathbf{2 2}, \mathbf{3 8}, 63,126,165,246, \mathbf{2 8 5}$ & 8 \\
\hline A/Wuhan/359/95 & $\mathbf{8}, \mathbf{2 2}, \mathbf{3 8}, 63,126,165,246, \mathbf{2 8 5}$ & 8 \\
\hline A/Sydney/5/97 & $\begin{array}{l}\mathbf{8}, \mathbf{2 2}, \mathbf{3 8}, 63,122,126,133,165,246 \\
\mathbf{2 8 5}\end{array}$ & 10 \\
\hline A/Panama/2007/99 & $\begin{array}{l}\mathbf{8}, \mathbf{2 2}, \mathbf{3 8}, 63,122,126,133,144,165 \\
246, \mathbf{2 8 5}\end{array}$ & 11 \\
\hline A/Fujian/411/02 & $\begin{array}{l}\mathbf{8}, \mathbf{2 2}, \mathbf{3 8}, 63,122,126,133,144,165, \\
246, \mathbf{2 8 5}\end{array}$ & 11 \\
\hline
\end{tabular}

NOTE: Numbers in bold represent conserved glycosylation sites found in the stalk of the influenza hemagglutinin protein. Non-bold numbers represent glycosylation sites acquired during the evolution of the virus. 
Table 2. Acquisition of glycosylastion sites in influenza B viruses

\begin{tabular}{lccccc}
\hline \multicolumn{1}{c}{ Virus } & Lineage 145 & 195-197 & 231-233 & $\begin{array}{c}\text { Total Potential } \\
\text { Sites }\end{array}$ \\
\hline B/Hong Kong/73 & I & Yes & No & No & 7 \\
B/Hong Kong/8/73 & I & Yes & No & No & 7 \\
B/Singapore/222/79 & II & Yes & No & Yes & 7 \\
B/Victoria/2/87 & III & Yes & No & No & 6 \\
B/Yamagata/16/88 & II & Yes & No & Yes & 7 \\
B/Memphis/3/89 & III & Yes & No & No & 6 \\
B/Panama/45/90 & II & Yes & Yes & Yes & 8 \\
B/Houston/1/91 & II & Yes & Yes & Yes & 8 \\
B/Sichuan/8/92 & II & Yes & No & No & 6 \\
B/Beijing 184/93 & II & Yes & No & No & 6 \\
B/Memphis/5/93 & II & Yes & Yes & Yes & 8 \\
B/Nanchang/630/94 & III & Yes & No & No & 6 \\
B/Houston/2/96 & II & Yes & Yes & No & 7 \\
B/Memphis/12/97 & II & Yes & Yes & No & 7 \\
B/Nanchang/2/97 & III & Yes & No & Yes & 7 \\
B/Yamanashi/166/98 & II & Yes & Yes & No & 7 \\
B/Maryland/1/01 & II & Yes & Yes & No & 7 \\
B/Nebraska/2/01 & II & Yes & Yes & No & 7 \\
B/Los Angeles/1/02 & III & Yes & Yes & Yes & 8 \\
B/Memphis/13/03 & III & Yes & Yes & Yes & 8 \\
\hline
\end{tabular}


The results of these experiments demonstrated the following: (i) animals exposed to a glycosylated virus remain susceptible to infection and mortality by a nonglycosylated influenza virus, (ii) a heavily glycosylated virus may induce an inferior and non-neutralizing antibody response, and (iii) in a scenario of low antibody crossreactivity, T-cell pathology can ensue. In conclusion, we suggest that exposure to a glycosylated virus prior to exposure to a non-glycosylated virus can render a host deficient in protective antibodies, particularly neutralizing antibodies, and susceptible to T-cell-driven pathology and death. 


\section{Chapter 2: Materials and Methods}

Mice

Six- to eight-week-old female Balb/c mice (Jackson Laboratory, Bar Harbor, ME) were maintained in a Biosafety Level 2 facility in the Animal Resource Center at St. Jude Children's Research Hospital (Memphis, TN). Mice were allowed to acclimate for 5-7 days before beginning experiments. All experiments were approved by the Animal Care and Use Committee at SJCRH and were done under general anesthesia with inhaled isoflurane $2.5 \%$ unless otherwise noted.

\section{Viral Infections}

Mice were initially infected on day 0 with the appropriate virus. Mice were inoculated i.n. with $1 \times 10^{4} \mathrm{TCID}_{50}$ in $100 \mu$ l volume. Three weeks later (day 21), or 121 days in the case of delayed challenge, mice were inoculated i.n. with $1 \times 10^{6}$ TCID $_{50}$ in $100 \mu 1$ volume. Mice were monitored for morbidity (weight loss) and mortality (survival). Mice that lost more than $30 \%$ of their initial body weight were euthanized and recorded as dying that day.

\section{Lung Titers}

Mice were euthanized by $\mathrm{CO}_{2}$ asphyxiation. Lungs were aseptically harvested, washed twice in PBS, and placed in $500 \mu 1$ of sterile PBS. Lungs were then homogenized using an Omni Tissue Homogenizer (Omni International, Marietta, GA). Homogenates were pelleted for 5 minutes at 10,000 rpm. The supernatants were then serial diluted 10fold in MDCK infection media. MDCK monolayers were inoculated with $100 \mu 1$ of each dilution. Infection of individual wells was tested using a standard hemagglutination assay.

\section{Histological Examination}

Lungs were removed immediately following euthanasia, inflated, and fixed in $10 \%$ neutral buffered formalin overnight. The lungs were processed routinely, embedded in paraffin, sectioned at $5 \mu \mathrm{m}$, stained with hematoxylin and eosin or CD3, and examined microscopically for histopathologic alterations. 


\section{Serum Collection and Treatment}

Clotted blood collected from the retro-orbital plexus of anesthetized mice 20 or 120 days after initial infection were centrifuged for $10 \mathrm{~min}$ at $6000 \mathrm{x} \mathrm{g.} 100 \mu 1$ serum was treated with $300 \mu 1$ receptor-destroying enzyme (RDE) (Denka Seiken CO. LTD., United Kingdom). $300 \mu 1$ of $2.5 \%$ sodium citrate and PBS were added and sera were used in immune assays.

\section{Immune Assays}

RDE-treated sera were analyzed for influenza-reactive antibody using standard HI titer, microneutralization, and ELISA assays. For HI assays sera and appropriate virus were incubated together for one hour. Chicken red blood cells were used to test for agglutination. Titers are reported as the reciprocal of the final serum dilution that did not inhibit hemagglutination.

For microneutralization assays, MDCK cells were inoculated with serum: virus mixtures and an antibody specific for influenza A virus nucleoprotein (antibody info) was used to detect infection of MDCK cells by the virus. Microneutralization titers are reported as the reciprocal of the final serum dilution that neutralizes virus to a level below one-half of the $\mathrm{OD}_{490}$ seen in virus control wells.

For ELISA, 96 well plates (Becton Dickinson and Company, Franklin Lakes, NJ, USA) were coated with appropriate concentrated virus and incubated overnight at $4^{\circ} \mathrm{C}$. Plates were washed and then blocked for 2 hours at RT. RDE-treated sera was serially diluted in blocking buffer through the plate and incubated overnight at $4{ }^{\circ} \mathrm{C}$. Plates were washed and incubated with $\operatorname{IgG}$, IgG1, or IgG2a antibodies (Southern Biotech, Birmingham, AL, USA) diluted in blocking buffer for 2 hours. Plates were washed and substrate buffer ( $\mathrm{p}$-nitrophenyl phosphate, Sigma) was added for 1 hour. Plates were read at $405 \mathrm{~nm}$ using Multiskan Ascent ${ }^{\circledR}$ plate reader (Labsystems, Helsinki, Finland). Reciprocal serum antibody titers were calculated at 50\% maximal binding.

\section{Broncho-Alveolar Lavage for Cell Counts}

Following euthanasia by $\mathrm{CO}_{2}$ inhalation, the trachea was exposed, nicked, and a catheter (Becton Dickinson and Company, Franklin Lakes, NJ, USA) was inserted into the nick. Lungs were lavaged twice with $1.5 \mathrm{ml}$ cold PBS+HBBS (Hanks' Balanced Salt Solution) (Mediatech Inc, Manassas, VA, USA). The total number of viable cells per $\mathrm{ml}$ was counted on a coulter counter using $100 \mu \mathrm{l}$ aliquot. Cells were then stained with T-cell antibodies and analyzed by flow cytometry. 


\section{Depletion of CD4+ and CD8+ T Cells}

Mice were depleted of CD4 (GK 1.5 mAb) or CD8 (2.43.1 mAb), or both, by intraperitoneal inoculation with $100 \mu$ l of appropriate antibody or both antibodies.

Depletion began 3 days prior to infection and inoculations were given every other day until 5 days after infection. Blood was collected from depleted mice to test for depletion as analyzed by FACS. 


\section{Chapter 3: Infection of Mice with a Highly Glycosylated Influenza Virus Followed by Challenge with a Virus Exhibiting Less Glycosylation Can Lead to Death}

To test the concept that glycosylation status is affecting the adaptive immune response towards influenza HA, we first looked to see if re-infection with a low glycosylated virus was possible after initial infection with a highly glycosylated virus. Since the two viruses are antigenically identical except for glycosylation status, reinfection should only be possible if glycosylation status is reducing the generation of adaptive immune responses. We therefore utilized three isogenic virus stocks with 0 (WT), $2(+2)$ and $4(+4)$ n-linked glycosylation sites on the globular head. Mice were infected on day 0 with +2 or +4 viruses $\left(1 \mathrm{X}_{10^{4}} \mathrm{TCID}_{50}\right)$ and then challenged on day 21 with WT $\left(1 \times 10^{6} \mathrm{TCID}_{50}\right)$. Figure 1 shows that mice initially infected with +4 lost a significant amount of weight upon WT challenge. However, mice initially infected with +2 lost no weight upon WT challenge. Mice initially infected with WT also showed no weight loss upon WT challenge (data not shown). Figure 2 shows the survival of these same mice. Over $80 \%$ of +4 infected mice succumbed to WT challenge, whereas none of the +2 infected mice succumbed to WT challenge. We therefore discovered that mice infected with +4 were not protected from WT challenge, demonstrating that exposure to a highly glycosylated virus can yield inferior protection against subsequent challenge with a non-glycosylated virus.

We then questioned whether the viral load was responsible for the weight loss seen in mice initially infected with +4 . To do this we looked at viral lung titers of mice previously exposed to $\mathrm{PBS}, \mathrm{WT},+2$, or +4 on days 1,3 , and 5 post-WT challenge. As shown in Figure 3, we found that +4 infected mice had detectable virus in their lungs only on day 1 after WT challenge, but that the virus had already started to be cleared on day 1 and was completely cleared by day 3 . We therefore discovered that the morbidity and mortality seen in +4 infected mice upon WT challenge could not be entirely explained by a higher viral load. 


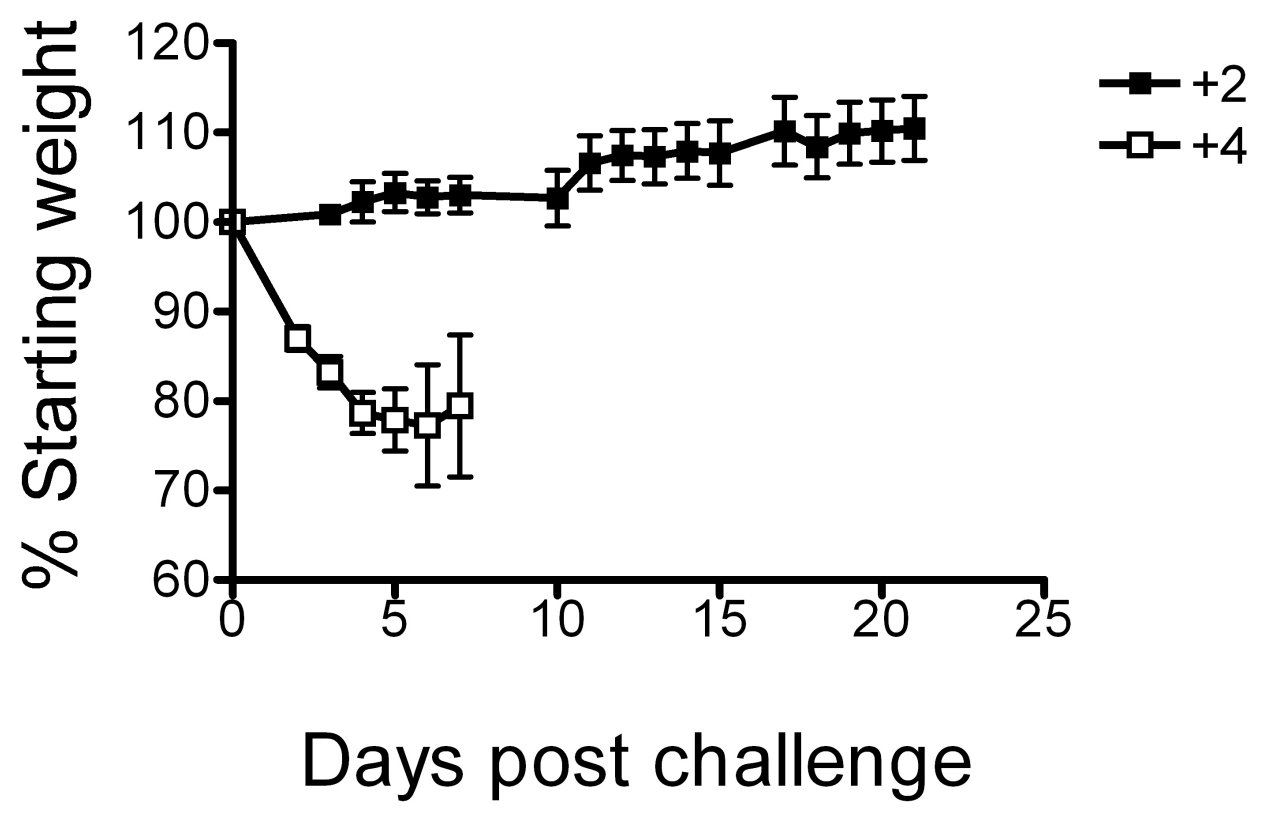

Figure 1. Mice infected with a highly glycosylated virus and re-infected with a virus exhibiting less glycosylation suffer weight loss. Mice were infected on day 0 with virus (see legend) and then challenged on day 21 with WT virus. Groups of 6 mice were infected with +2 or +4 virus. Surviving animals were weighted thereafter. ANOVA analyses demonstrated a significant difference $(\mathrm{P}<0.05)$ between mice infected with +4 and +2 viruses on days $2-5$. 


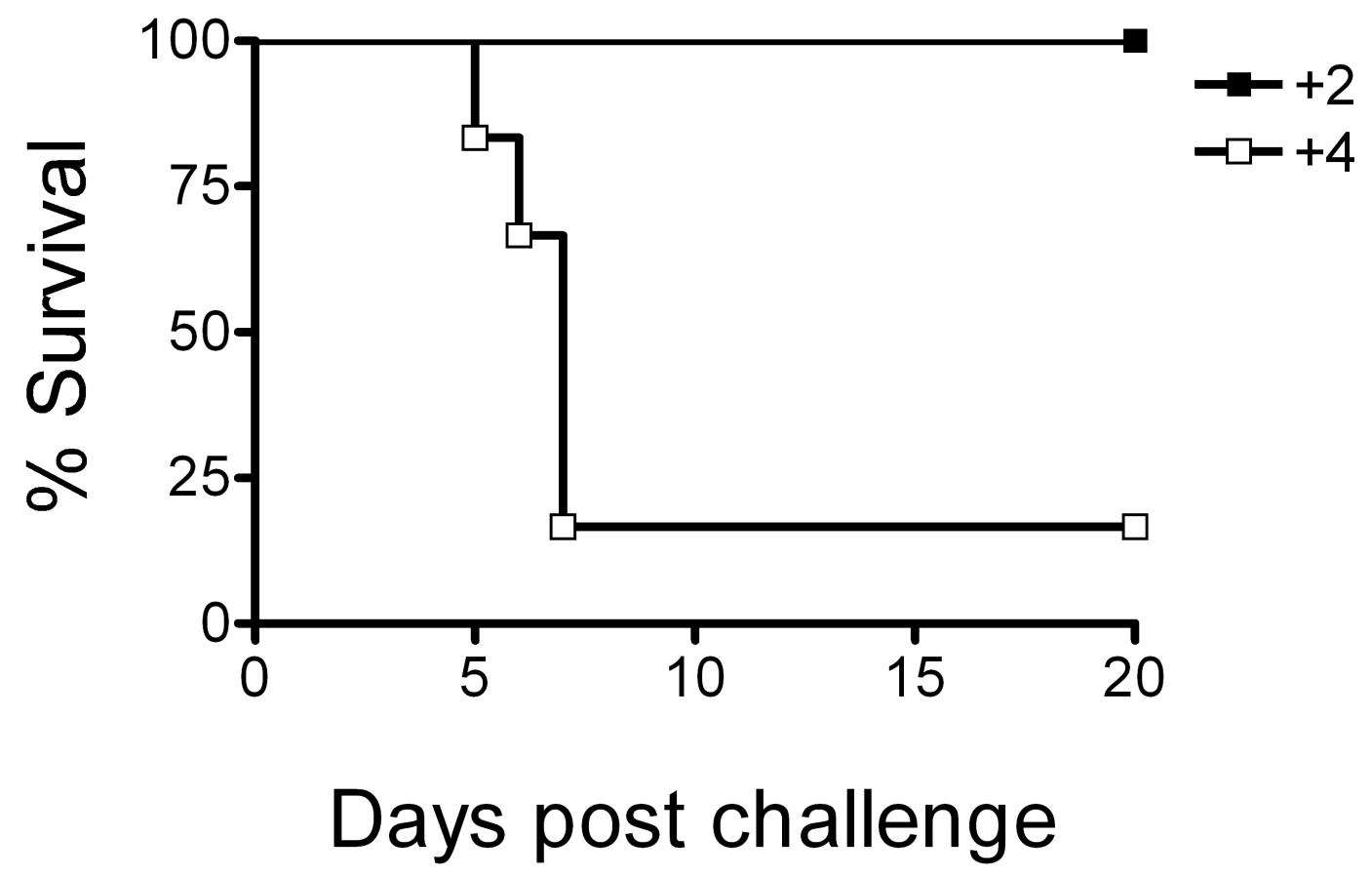

Figure 2. Mice infected with a highly glycosylated virus and re-infected with a virus exhibiting less glycosylation succumb. Mice were infected on day 0 with initial infection (see legend) virus then challenged on day 21 with WT virus. Groups of 6 mice were infected with +2 or +4 virus. Surviving animals were weighted thereafter. All but 1 +4 infected mouse succumbed by day 7 post challenge. The number of surviving mice within these groups was recorded over the observation period. 


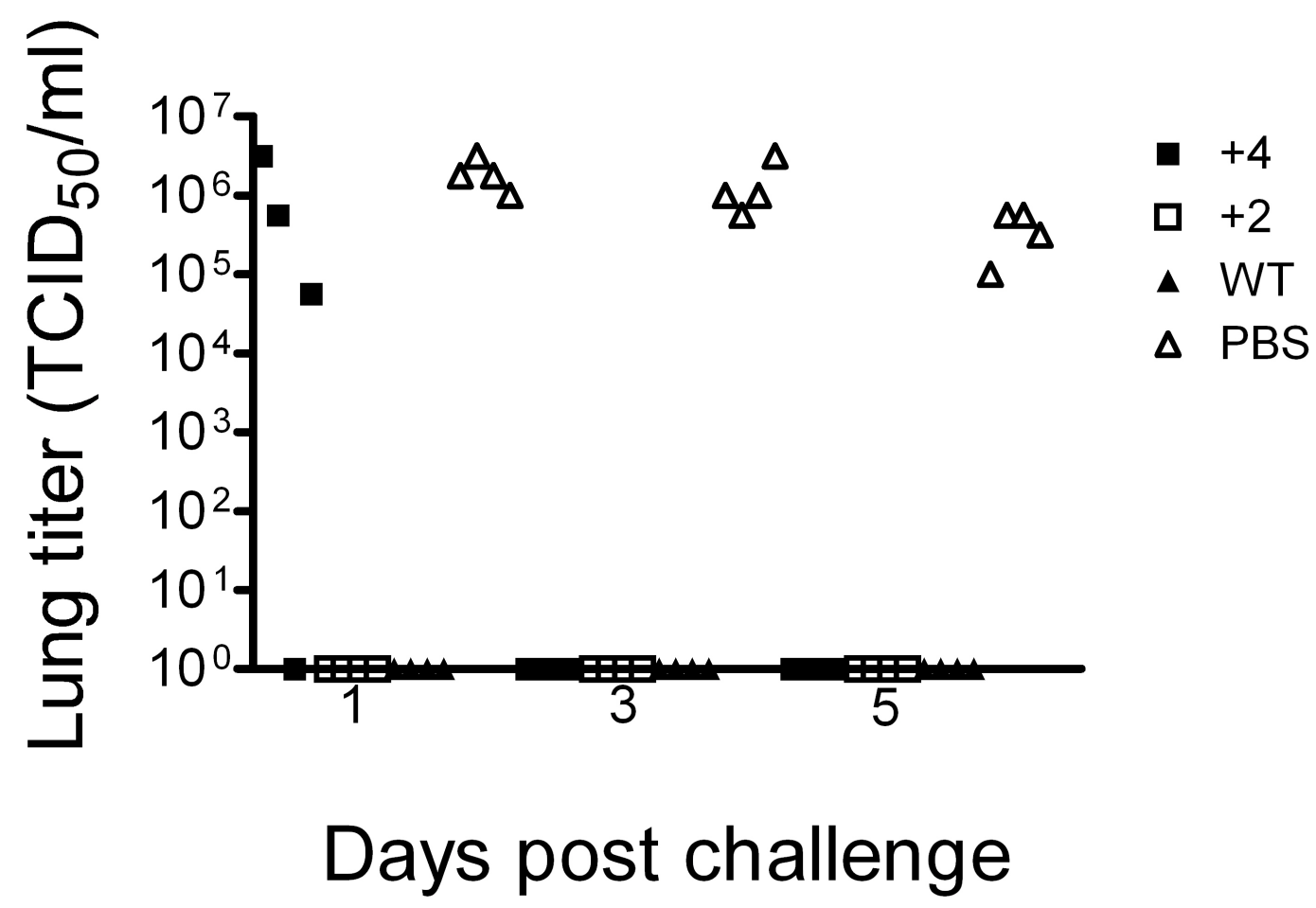

Figure 3. Regardless of initial infection, mice clear challenge virus from lungs by day 3. Mice were infected on day 0 with virus (see legend) and then challenged on day 21 with WT virus. Some animals were sacrificed at regular intervals thereafter for lung titers. Lungs were collected, homogenized, and plated on MDCK cells to assess viral lung titers from each group containing 4 mice. 


\section{Chapter 4: Protection in This Model Is Antibody Mediated}

We questioned whether the protection or lack of protection seen in the sequential infections was antibody related. To answer this question we used B-cell deficient mice to recapitulate the sequential infections. If the protection is antibody mediated, then +2 infected mice should now lose weight when challenged with WT in antibody deficient mice and +4 infected mice should show no changes. Therefore, muMT mice were infected with WT, +2 , or +4 and then challenged with WT on day 21 . Figure 4 shows that B-cell deficient mice are no longer protected from WT challenge and that there is a progressive pattern of disease dependent on glycosylation status. Figure 5 shows the survival of these same mice, $75 \%$ of mice initially infected with +4 succumbed to WT challenge, whereas all WT and +2 initially infected mice survived WT challenge. Therefore, protection from WT challenge is at least partially dependent on antibodies, although the progressive disease pattern and the recovery of WT and +2 infected mice around day 3 suggest that $\mathrm{T}$ cells may also be important for protection. 


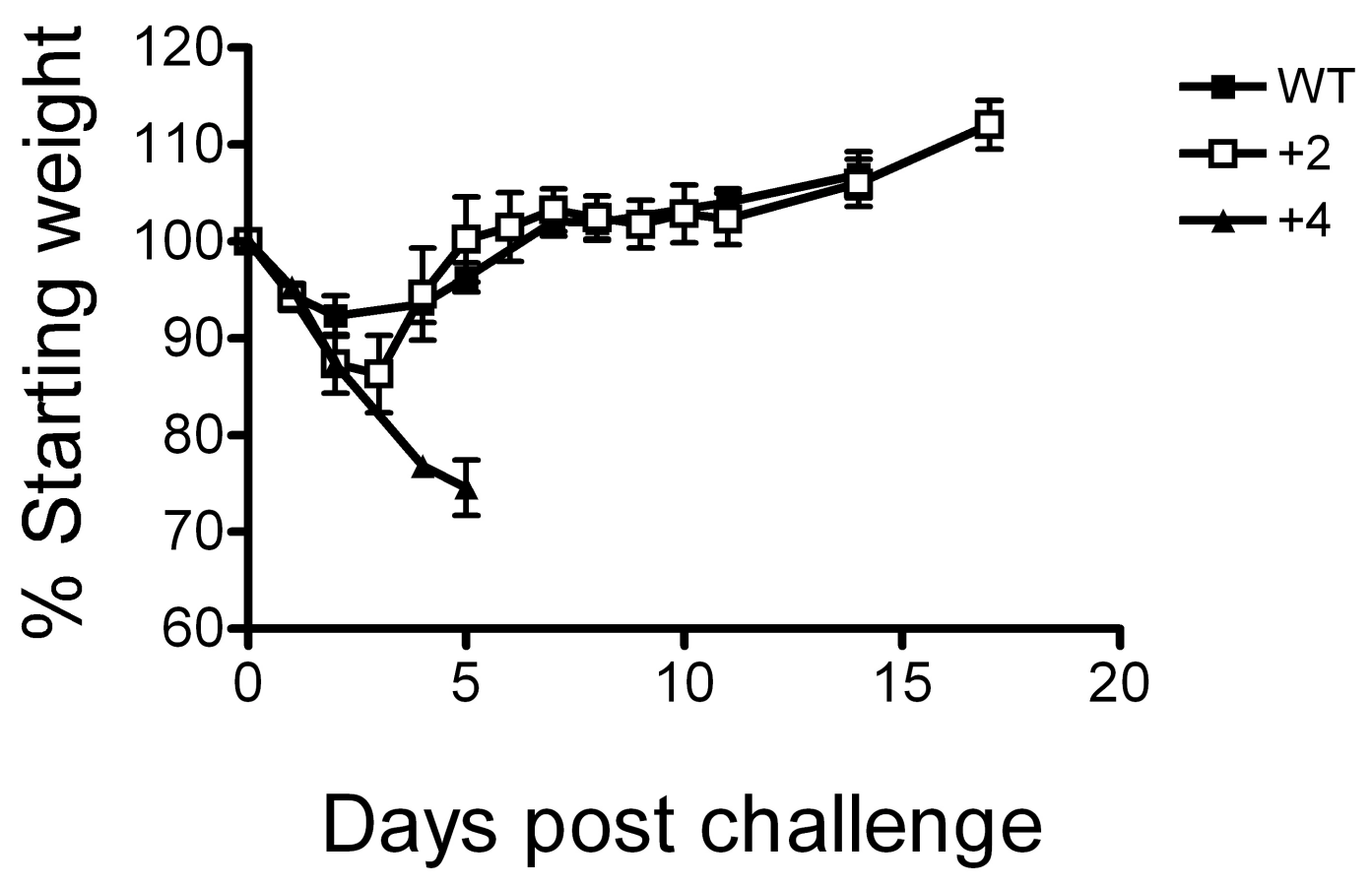

Figure 4. Protection conferred by +2 and WT viral infection against weight loss is antibody mediated. B-cell deficient mice were infected as described in Figure 1. Groups of 4 mice were infected with $+4,+2$, or WT virus before challenge with WT virus. Mice were then followed for weight loss. ANOVA analyses show a significant difference $(\mathrm{P}<0.05)$ between +4 and other groups on days $4-5$. 


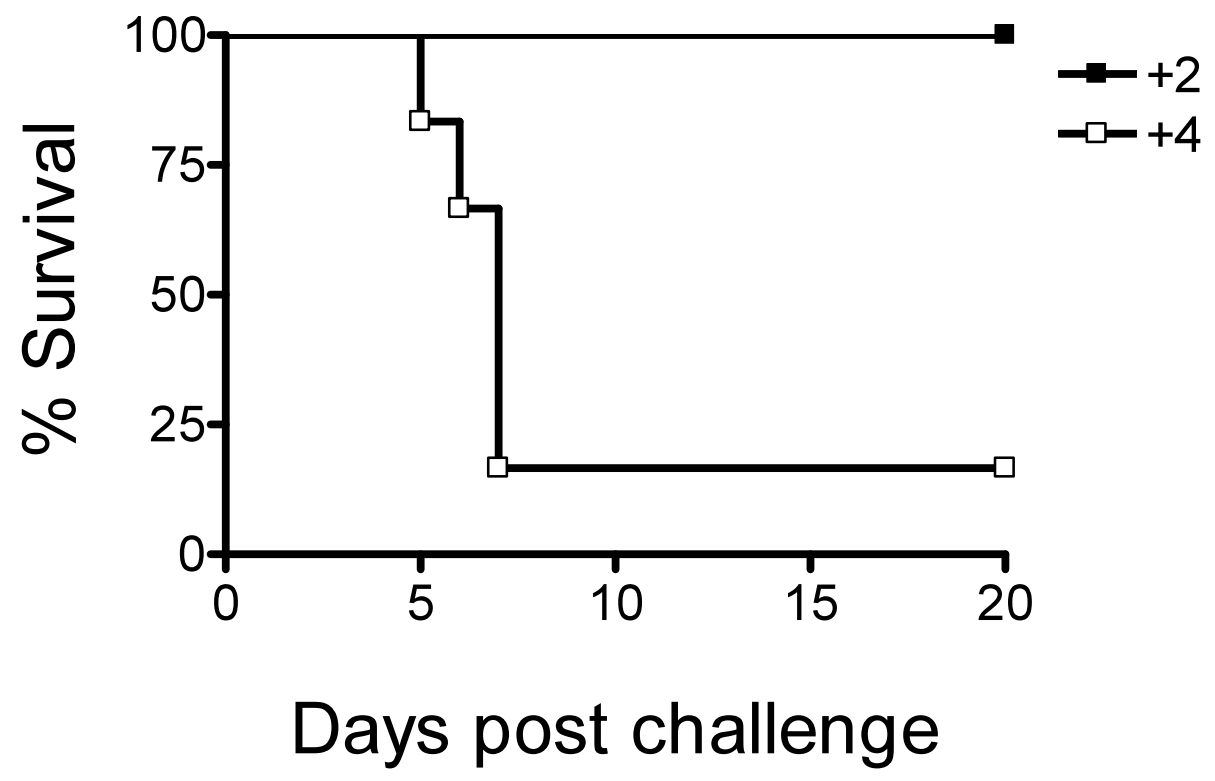

Figure 5. Survival outcome in muMT animals. The number of surviving mice within these groups was recorded over the observation period. All but $1+4$ infected mice succumbed by day 7 post challenge. 


\section{Chapter 5: Increasing Glycosylation Leads to a Decreased Antibody Response}

We next looked at the specific antibody responses that were affected by glycosylation status. We questioned whether glycosylation was affecting antibody quality or quantity, or whether it was a specific antibody deficit or a general one. To do this, mice were infected with WT, +2 , or +4 virus on day 0 and then bled for sera on day 20. This sera was then used in various immune assays to determine the antibody response to each of these viruses. Figure 6a shows a Hemaglutination Inhibition Assay (HAI) with WT as a target. Mice initially infected with +4 show less inhibition of WT HA than mice initially infected with WT or $+2(+2$ data not shown). Since HAI assays are not very specific and do not show the quality of antibody, we looked at microneutralization of influenza specific to WT. Figure $6 \mathrm{~b}$ shows that +4 infected mice show almost no neutralization of WT and that +4 infected mice show significantly less ability to neutralize WT than mice initially infected with WT or $+2(+2$ data not shown). Next, we wanted to look at the amount of IgG generated by the glycosylation mutants. ELISAs were performed with an IgG antibody to detect the levels of IgG antibodies specific to WT. Figure $6 \mathrm{c}$ shows that in +4 infected mice there is less IgG specific to WT; +2 infected mice show a titer between that of +4 infected mice and WT infected mice ( +2 data not shown). Since, microneutralization showed that these viruses differed in their ability to neutralize WT virus, we decided to also look at the amount of IgG2a generated, as this subtype is generally associated with non-neutralizing antibodies. ELISAs were again performed with an IgG1 and IgG2a antibody to determine its levels to the target virus. As previously demonstrated, mice initially infected with +4 elicited less of a response against WT (data not shown). These same immune assays were then run with +4 virus as the target. Figure $6 \mathrm{~d}$ shows hemagglutinin inhibition against +4 virus is the same regardless of initial infection virus. Figure 6e shows the same holds true for microneutralization. Neutralization of +4 virus is very low regardless of infecting virus and is very low even in the case of homologous challenge. Figure $6 \mathrm{f}$ shows the levels of IgG against +4 virus. This also holds true for IgG1 and IgG2a (data not shown). In each case WT infected mice show a higher titer than +4 infected mice. In general these data show, the more glycosylated a virus is the less of an antibody response it will induce. This is most significant in the case of neutralizing antibodies as +4 has almost no ability to neutralize WT and even shows little ability to neutralize itself. Therefore glycosylation is reducing the overall quantity and quality of antibody response. 
a

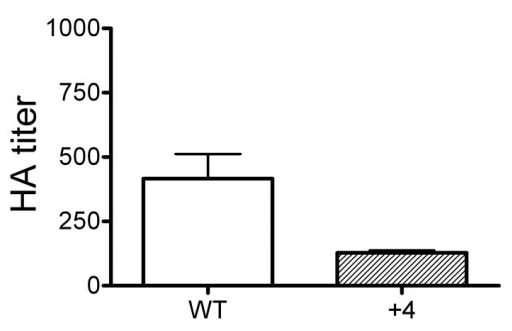

b

Mouse inoculating virus

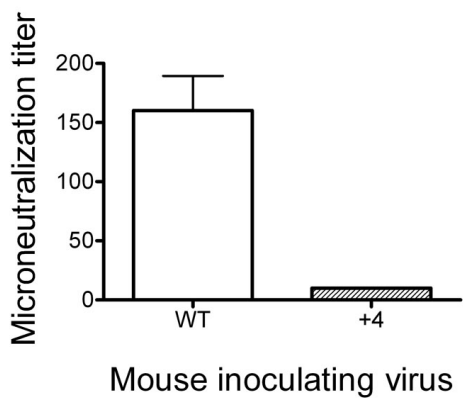

C

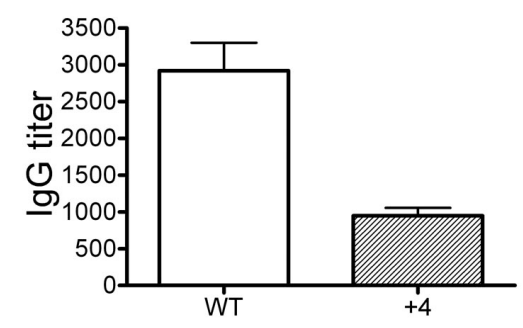

Mouse inoculating virus d
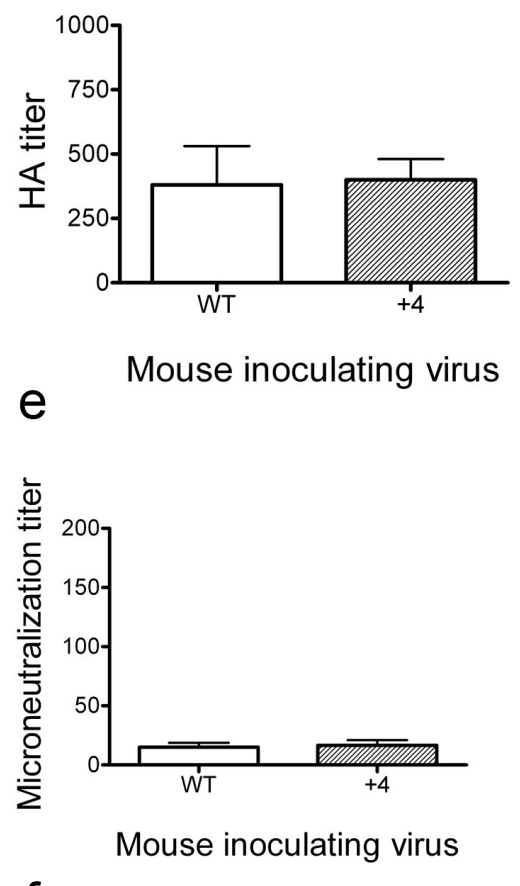

$f$

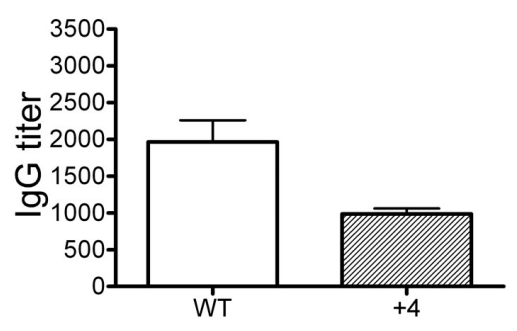

Mouse inoculating virus

Figure 6. +4 infected mice elicit lower antibody response than +2 and WT infected mice when assessed with WT as the target virus. Mice were infected on day 0 with virus (see legend), bled for sera on day 20, and then assessed for various immune responses against WT. (a) Hemagglutinin Inhibition Assay (b) Microneutralization Assay (c) IgG ELISA. Mice were also assessed for the same immune responses against +4. (d) Hemagglutinin Inhibition Assay (e) Microneutralization Assay (f) IgG ELISA. ANOVA analyses (between groups comparisons) showed statistically significant differences between +4 responses and wt responses toward wt $(p<.05)$ in assays for hemagglutination inhibition, microneutralization and ELISA titer. 


\section{Chapter 6: T-Cell Responses after Virus Challenge}

\section{T-Cell Response in This Model Can Be Both Harmful and Protective}

After seeing that glycosylation status had a clear effect on antibody formation, we then questioned whether there was a similar effect on T cells. We wanted to test the concept that $\mathrm{T}$ cells contributed to the antibody related protection seen in this model. To determine if T cells were necessary for protection on WT challenge, mice were depleted of both $\mathrm{CD} 4+$ and $\mathrm{CD} 8+\mathrm{T}$ cells. Figure 7 a shows that +2 infected mice were still protected from WT challenge. Surprisingly, +4 infected mice when depleted of T cells on WT challenge were also protected, suggesting that the pathology may be T-cell mediated. To determine if $\mathrm{CD} 4+$ or $\mathrm{CD} 8+\mathrm{T}$ cells were responsible for this effect, +4 infected mice were depleted of either CD4+ or $\mathrm{CD} 8+\mathrm{T}$ cells on WT challenge. Figure $7 \mathrm{~b}$ shows that this effect is mediated by both $\mathrm{CD} 4+$ and $\mathrm{CD} 8+\mathrm{T}$ cells, seemingly equally. Therefore the pathology seen in mice first infected with a highly glycosylated virus and then challenged with WT is T-cell mediated.

\section{Highly Glycosylated Virus Leads to More Lung Pathology and Greater T-Cell Influx upon Challenge with WT}

After seeing that mice initially infected with +4 caused more weight loss than initial infection with +2 or WT, we wanted to see the pathological effects on the lung as well as the T-cell influx in the lung of these same infections. To examine the histological features associated with successive infection, mice were infected on day 0 with $+4,+2$, WT, or were mock-infected (PBS); mice were then challenged on day 21 with WT. Three days after challenge, lungs were harvested and stained for pathological examination. Figure $8 \mathrm{a}, \mathrm{b}, \mathrm{c}$, and d show that the degree of pathology was directly associated with the level of glycosylation of the initial infection virus. Lungs from mice infected with +4 show a greater degree of pathology than all other groups including mock-infected mice. The pathology upon WT challenge decreased as the level of glycosylation of the initial infection decreases. Lungs from the same mice were also stained for CD3, a marker. Figure $9 \mathrm{a}, \mathrm{b}$ and $\mathrm{c}$ shows that the amount of T-cell infiltrate in the lung was directly related to the glycosylation status of initial infection. Mice initially infected with +4 showed the greatest amount of CD3 staining followed by +2 (data not shown), WT, and finally mock-infected. These data show that in the case of successive infection, lung injury possibly due to greater T-cell response was exacerbated by the glycosylation status of the initial infection. To further confirm this, mice were again infected and challenged as previously described. On day 3 after challenge, broncho-alveolar lavage fluid (BAL) was collected and stained with anti-CD3 antibodies, anti-CD4 antibodies, and anti-CD8 antibodies. FACS analysis was then performed to determine the relative number of total $\mathrm{T}$ cells, $\mathrm{CD} 4+\mathrm{T}$ cells, and $\mathrm{CD} 8+\mathrm{T}$ cells. 


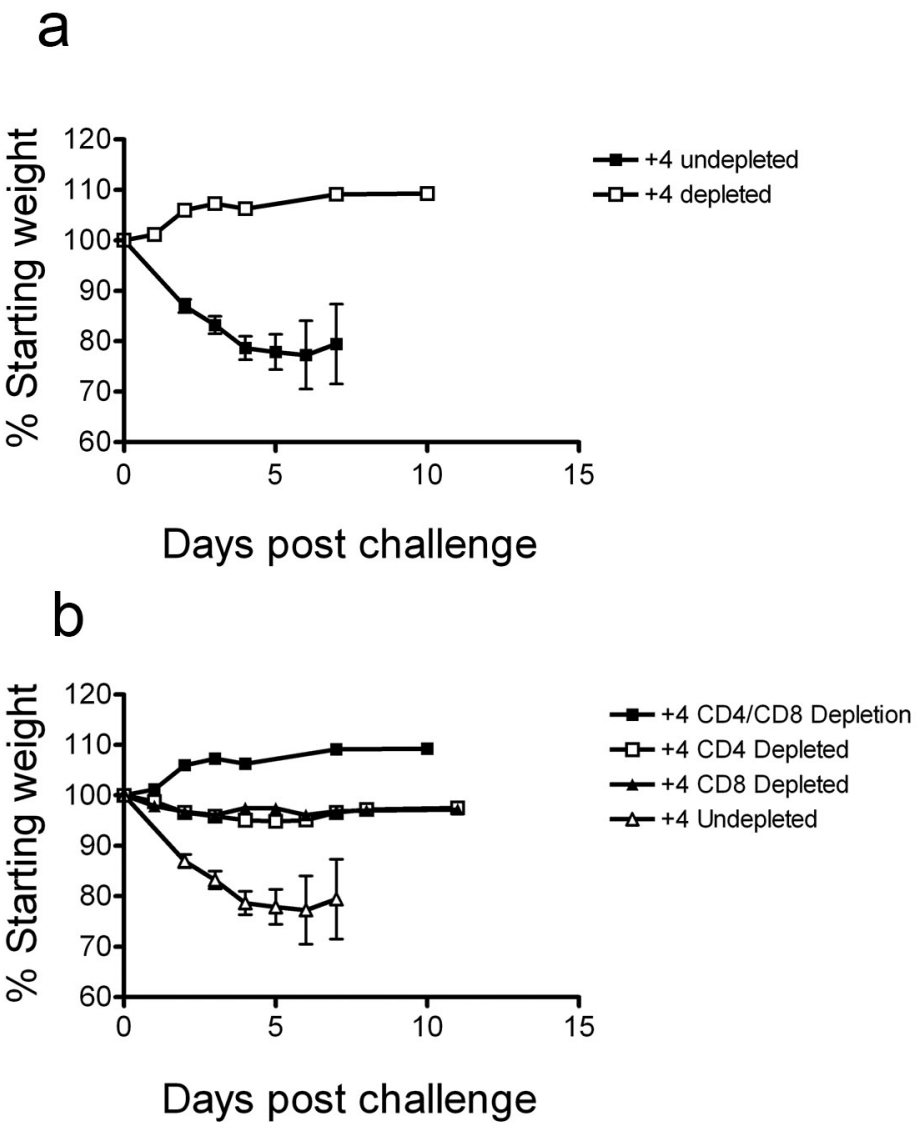

Figure 7. Depletion of T cells upon WT challenge abolishes weight loss and death. Mice were infected as described previously. (a) +4 infected mice were depleted of both CD4+ and CD8+ T cells upon WT challenge at regular intervals and depletion was analyzed by FACS. (b) +4 infected mice were depleted of different subsets of T cells (see legend) upon WT challenge at regular intervals and depletion was analyzed by FACS. ANOVA analyses showed a significant difference $(\mathrm{P}<0.05)$ between the undepleted group and all other groups on days 2-5. 
a

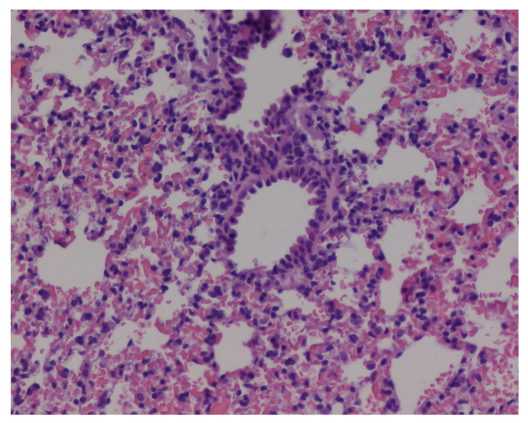

C

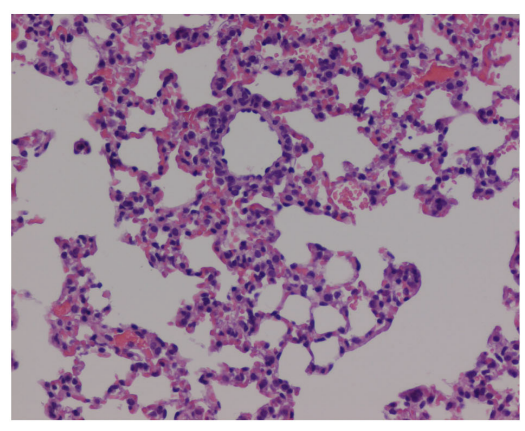

b

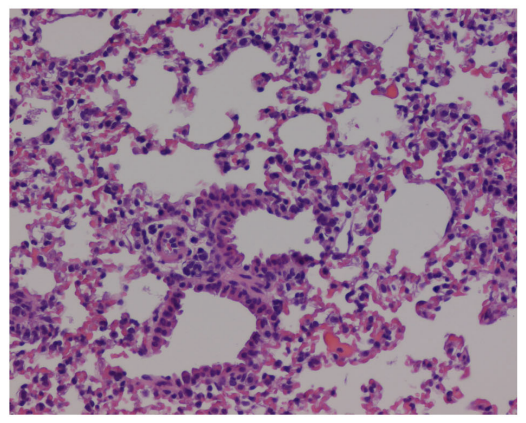

d

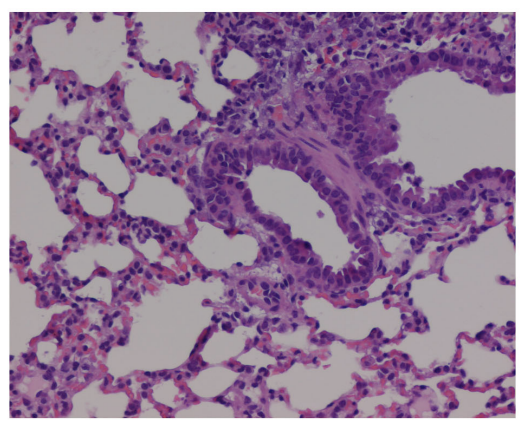

Figure 8. +4 infected mice show the greatest degree of lung damage 3 days post WT challenge. Mice were infected on day 0 with $+4,+2$, WT, or PBS (mock-infected) and challenged on day 21 with WT. 3 Days post WT challenge lungs were harvested and stained for $\mathrm{H}+\mathrm{E}$ to assess lung damage. (a) +4 infected mice (b) +2 infected mice (c) WT infected mice (d) PBS (mock-infected) mice. 

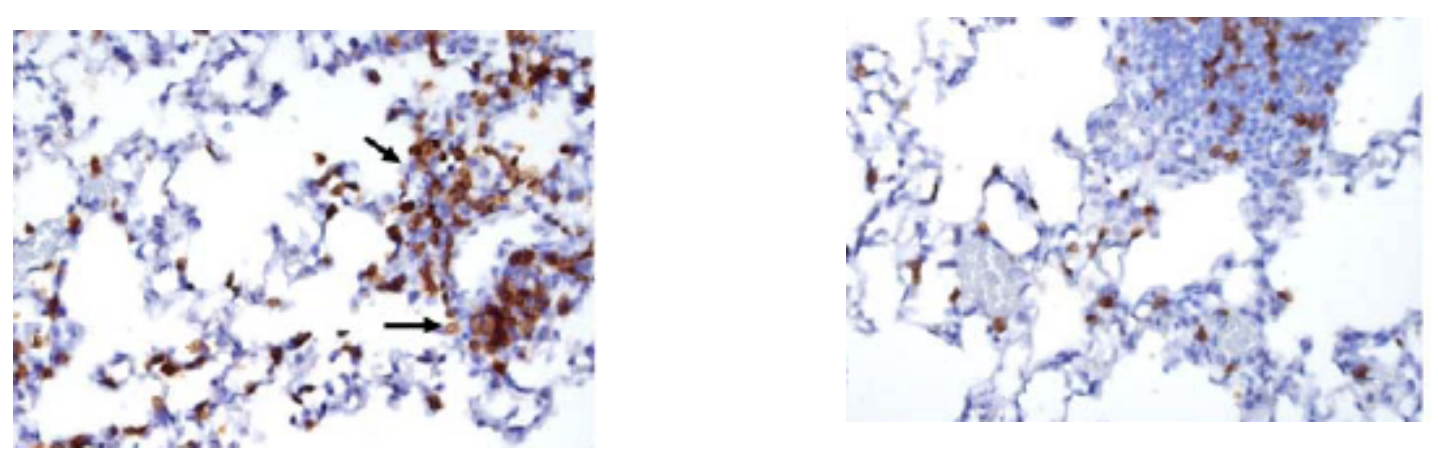

c

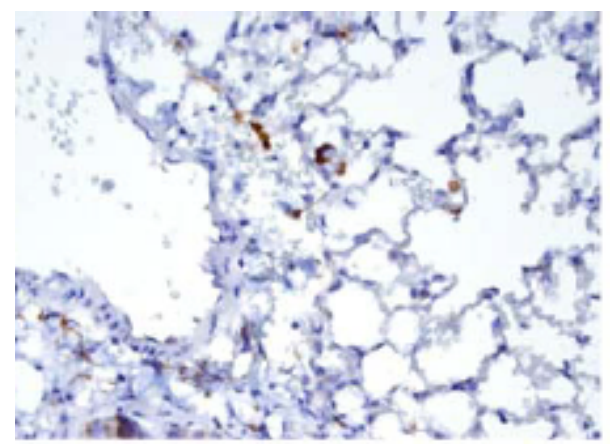

Figure 9. +4 infected mice show the greatest amount of T-cell influx 3 days post WT challenge. Mice were infected and lungs were harvested as in Figure 5. Lungs were stained for CD3 to assess the influx of T cells. (a) +4 infected mice (b) WT infected mice (c) PBS (mock-infected) mice. Arrows indicate high CD3 staining. 
Figure 10a shows the total number of CD3+ cells for each group. Mice infected with +4 showed the highest amount of CD3 + T-cell influx in the lung, confirming previous findings. Other groups show similar amounts of CD3+ T cells. Figure 10b shows the amount of CD4+/CD8- T cell found in BAL fluid. As described previously, +4 initially infected mice showed the highest number of CD4+/CD8- with the other groups having similar numbers of T cells. Figure 10c shows the number of CD4-/CD8+ T cells found in the BAL of each group. Mice infected with +4 again showed the highest number of CD4-/CD8+ T cells with a stepwise increase in this T-cell subset dependent on glycosylation status of the initial infection virus. These data show that +4 infected mice have the greatest T-cell influx in the lung, as measured by three different T-cell subsets. 
a
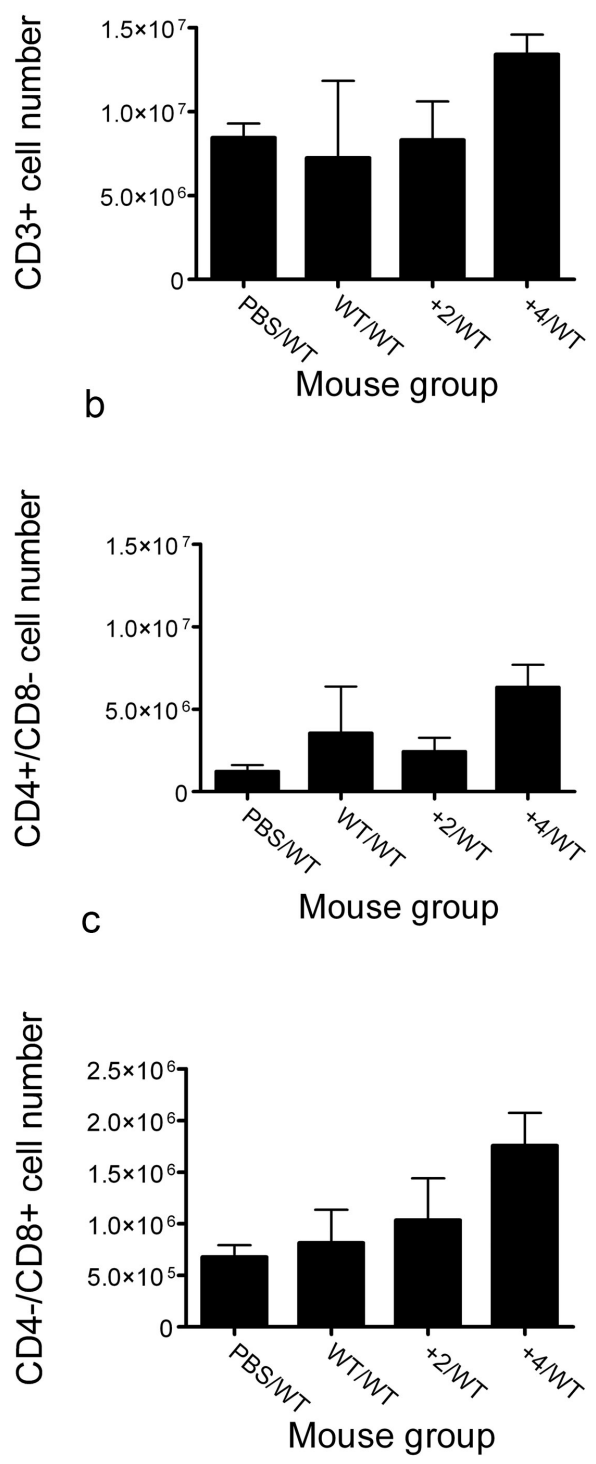

Figure 10. +4 infected mice show the greatest amount of $T$-cell infiltrate in the lungs. Mice were initially infected with $+4,+2$, WT, or PBS (mock infected) and challenged with WT on day 21 as previously described. BAL fluid was collected from mice 3 day post WT challenge and stained with antibodies for CD3, CD4, and CD8 to assess the amount of T-cell infiltrate in the lungs. Samples were analyzed by FACS. (a) Number of CD3+ cells (b) Number of CD4+/CD8- cells (c) Number of CD4-/CD8+ cells. ANOVA analyses showed a significant difference $(\mathrm{P}<0.05)$ between +4 and other groups when CD3+ cells were compared. 


\section{Chapter 7: Effect of Infection with a Heavily Glycosylated Virus on Delayed Challenge with a Virus Exhibiting Less Glycosylation}

\section{Delayed WT Challenge Has No Effect on Pathology in +4 Infected Mice but Abolishes Protection Seen in +2 Infected Mice}

To determine the long term consequences of successive infection, mice were infected with either +2 or +4 virus as previously described. WT challenge was then delayed until day 121. Mice were bled on day 120 to assess immune function. Subsets of these mice were also depleted of CD4+ and CD8+ T cells on WT challenge as previously described. Figure 11 shows that delayed WT challenge had no effect on the pathology associated with initial +4 infection. Alternatively, +2 infected mice upon delayed WT challenge now showed pathology similar to that seen previously only in +4 mice. Also as described previously, T-cell depletion on WT challenge abolishes the pathology seen in this model.

\section{WT Virus Elicits an Improved Immune Response Compared to +4 Virus at the Day 120 Time Point}

Figure 12a (hemagglutination inhibition), 12b (microneutralization), and $12 \mathrm{c}$ (IgG ELISA) show immune assays from sera collected at day 120 . As seen previously, +4 initially infected mice generate lower responses on all immune assays, with +2 infected mice showing more (data not shown), and WT showing the greatest response. Interestingly, comparing day 120 immune responses (Figure 12) with day 20 immune responses (Figure 6) shows an overall increase in immune responses over time regardless of initial infecting virus. 


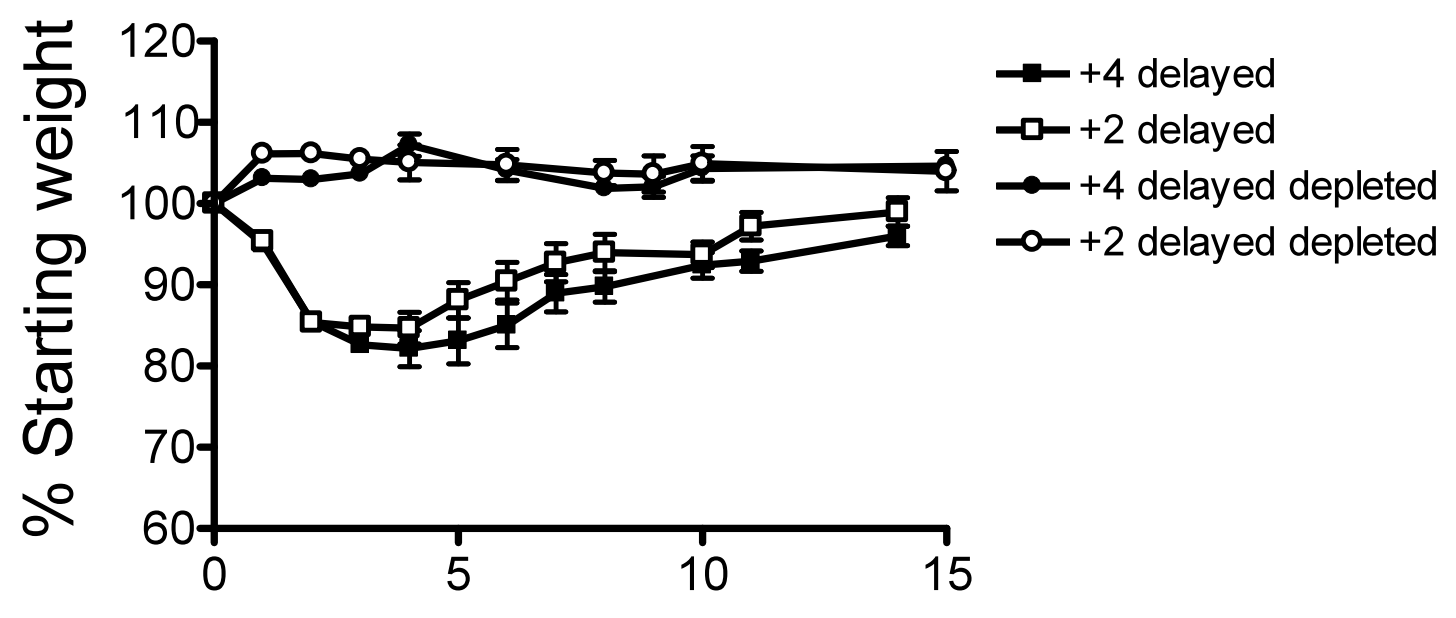

\section{Days post challenge}

Figure 11. Delayed WT challenge has no effect on pathology seen in +4 infected mice but leads to a loss of protection in the case of +2 infected mice. Mice were infected with +4 or +2 virus as described previously. Mice were then bled on day 120 and challenged with WT on day 121. Sera from these mice were then used for immune assays. Some mice were depleted of CD4+ and CD8 + T cells on WT challenge. +4 and +2 infected mice (depleted and undepleted) were followed for weight loss after WT challenge. 

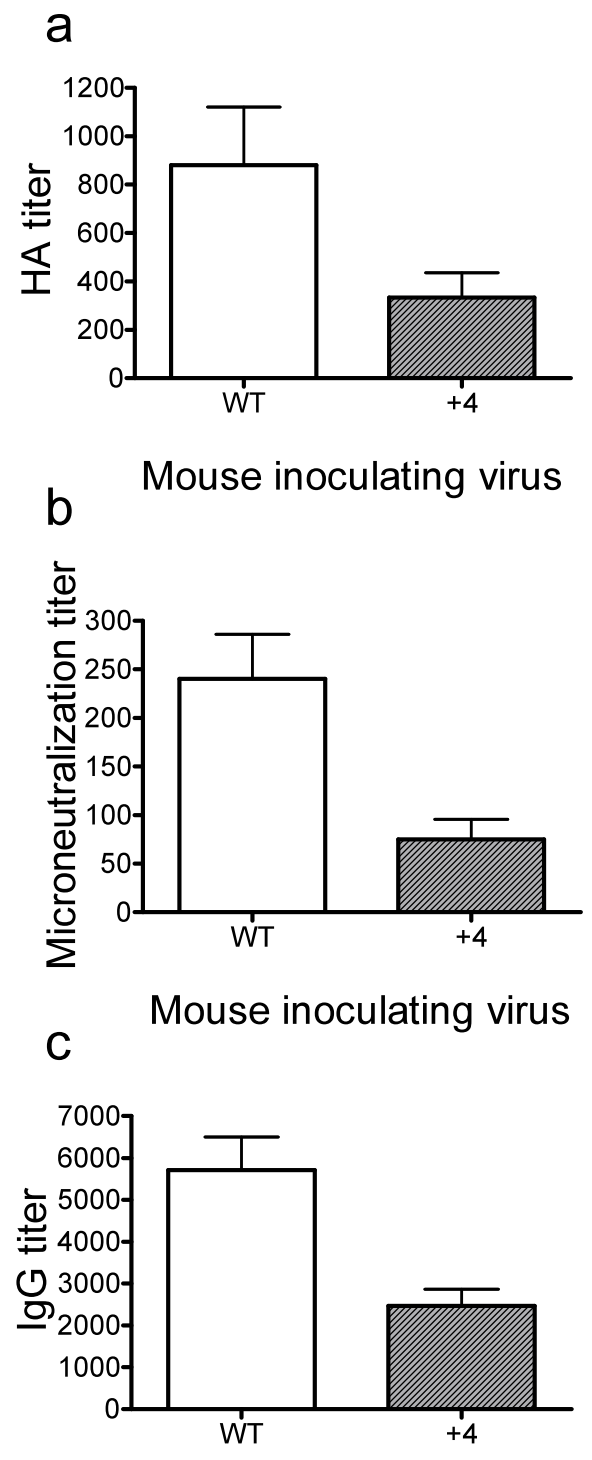

Mouse inoculating virus

Figure 12. WT virus elicits an improved immune response compared to +4 virus at the day 120 time point. Mice were infected with WT or +4 virus as previously described. Mice were then bled on day 120 and challenged. Sera from these mice were then tested in (a) Hemagglutination Inhibition Assay (b) Microneutralization Assay and (c) IgG ELISA 


\section{Chapter 8: Mice Suffer Pathology When Infected with a Seasonal H1N1 Isolate and Then Challenged with the S-OIV Swine Influenza, a Virus Exhibiting Less Glycosylation}

To look at the consequence of these successive infections in a model similar to that of the current S-OIV pandemic, mice were initially infected with Beijing/262/95 (Bei) a seasonal isolate of H1N1 or with California/04/09 (Cali or S-OIV) a novel swine isolate. Mice were then challenged with S-OIV and followed for weight loss. Figure 13a shows that mice initially infected with the seasonal isolate lose weight upon S-OIV challenge while those initially infected with S-OIV did not. Figure $13 \mathrm{~b}$ and $13 \mathrm{c}$ show the lung pathology associated with these infections. Mice initially infected with the seasonal isolate showed a greater degree of lung pathology upon S-OIV challenge. Figure 14a and $14 \mathrm{~b}$ show $\mathrm{CD} 3+$ staining of these same mice. Again, mice initially infected with the seasonal isolate showed a greater influx of $\mathrm{CD} 3+$ cells. 


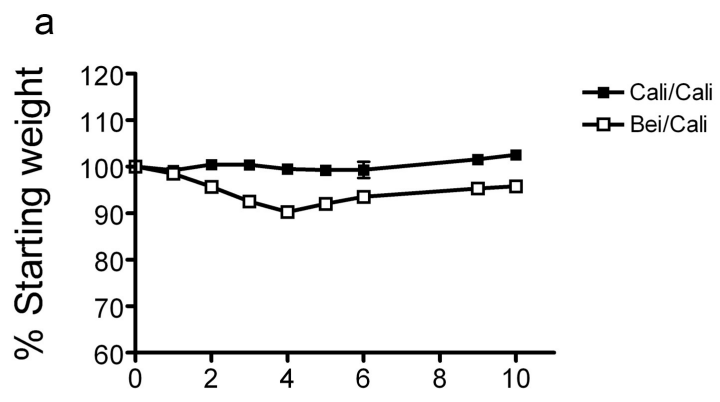

Days post challenge

b

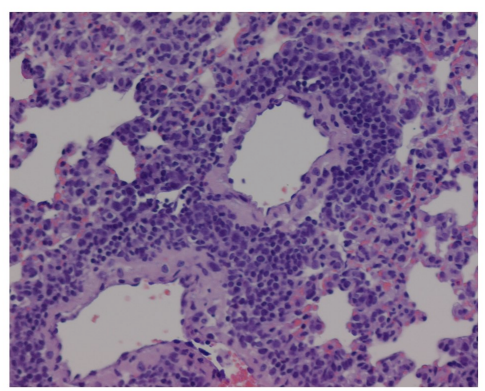

d

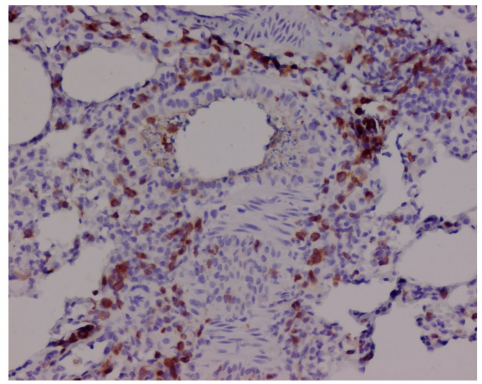

C

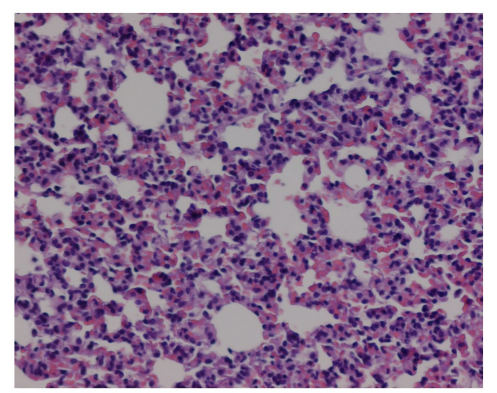

e

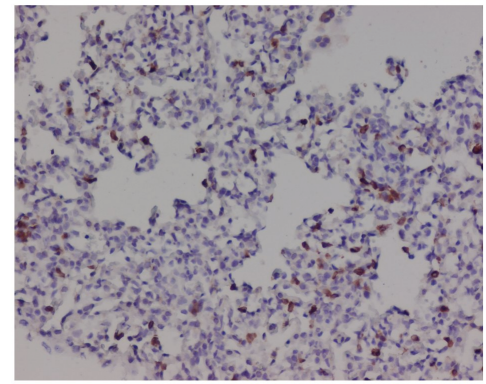

Figure 13. Mice suffer pathology when infected with a seasonal H1N1 isolate and then challenged with S-OIV. (a) Mice infected with a highly glycosylated H1N1 virus (Beijing/262/95) (Bei) can be re-infected with a non-glycosylated H1N1 virus (California/04/09) (Cali). Mice were infected on day 0 with Bei or Cali and then were challenged with Cali on day 21. (b) Lung histology $(\mathrm{H}+\mathrm{E})$ from mice infected with Bei then challenged with Cali (c) Lung histology $(\mathrm{H}+\mathrm{E})$ from mice infected with Cali then challenged with Cali (d) Lungs stained with CD3 after Bei/Cali infection (d) Lungs stained with CD3 after Cali/Cali infection. ANOVA analyses showed a significant difference $(\mathrm{P}<0.05)$ between Cali-infected and Bei-infected mice on day 2 and thereafter. 


\section{Chapter 9: Impact of Results on Scientific Understanding and Future Goals}

\section{Glycosylation and the Evolution of Influenza Virus}

As each influenza subtype has evolved in the human population, they have gradually acquired more potential N-linked glycosylation sites around the globular head of the HA protein (see table 1). On the other hand, the number of N-linked glycosylation sites in the stalk region of the HA have stayed relatively constant as they are involved in the folding and conformation of the protein. This illustrates another common factor found in past human influenza pandemics, the lack of n-linked glycosylation on the globular head of HA. Each of the virus subtypes (H1N1, H2N2, and H3N2) of past pandemics has acquired additional N-linked glycosylation sites as they have evolved in the human population (see table 1).

As previous studies in our lab have shown, one effect of increased glycosylation was decreasing virulence due to enhanced clearance by innate immune responses [9]. We proposed that this was the cost associated with evasion of the host adaptive immune response. We used a series of viruses that differed only with respect to their glycosylation status to examine the effect of successive infections on the adaptive immune response. We demonstrate here that highly glycosylated virus cannot protect against subsequent challenge with non-glycosylated virus. This lack of protection is due to a lack of neutralization capability and also leads to T-cell-mediated pathology. Specifically, we believe that glycosylation is selectively blocking neutralizing antibody epitopes. As we can see from these data, +4 infected mice have an IgG response towards WT despite being lower than other viruses. The biggest differences were seen in the microneutralization assay, where +4 infected mice showed almost no ability to neutralize WT. In fact, prior infection with a highly glycosylated virus leads to greater lung injury and T-cell pathology upon WT challenge than no prior infection at all. These data indicate that glycosylation can inhibit cross-reactivity against an otherwise isogenic nonglycosylated virus.

The idea that glycosylation of viral proteins could cause a defect in the formation of neutralizing antibodies against said protein is not new. It has been shown in Simian Immunodeficiency Virus (SIV) that glycosylation of gp41 can shield epitopes that are targets for neutralization [12]. Removing these glycosylation sites leads to enhanced neutralization [12]. Further studies with SIV show similar enhanced neutralization with a deglycosylated gp120 mutant, although host factors also seem to play a role [13].

Similarly, in Human Immunodeficiency Virus (HIV) removal of one N-linked glycan from gp120 results in enhanced ability to induce neutralizing antibodies [14]. It has been widely shown in the HIV field that neutralizing antibodies play an important role in protection against HIV and that the generation of these neutralizing antibodies is difficult, possibly due to glycosylation (reviewed in [15]). For many viruses, including influenza, the generation of neutralizing antibodies is a key part of vaccine development [14-16]. The clear deficit in neutralization seen in these studies leads us to conclude that the main role of glycosylation on the globular head of influenza HA is to block the formation of 
neutralizing antibodies. Recent research has shown that neutralizing antibodies against H3N2 viruses can be divided into three main groups. These groups are divided by year with 1968-1973, 1977-1993, and 1997-2003 being the years that the antibodies could effectively neutralize. In other words, antibodies that neutralize one group were not efficient in neutralizing virus outside of that range of years [17]. These ranges of years correlate quite well with the addition of glycosylation sites (table 1). 1973 marks the addition of a site as well as the end of one neutralization group, 1977 marks the inclusion of a second site, and 1997 marks the addition of a third site. It is interesting to note, especially in light of the data shown here, that the addition of glycosylation seems to strongly correlate with the need for different neutralizing antibodies. By evading neutralization, the virus can still set up an infection allowing for some replication and viral transmission. This can be seen in the case of mice initially infected with +4 virus which show signs of virus in the lungs on day 1 (Figure 3 ) despite any signs of non Tcell-mediated pathology. In other words, there is virus present in the host as a subclinical infection that still allows viral transmission. This is the ideal situation for any virus, allowing the virus to multiply and spread without harming the host. The studies in this paper and those performed previously in this lab suggest this is the one possible consequence of glycosylation in the context of influenza, as glycosylated viruses have been shown to be less virulent and to elicit less of an antibody response.

\section{Influenza Virus Glycosylation and Disease}

Recently the human population has faced the threat of another influenza pandemic, the H1N1 swine-origin virus (S-OIV). Despite the fact that flu season had just started, there were 8651 confirmed deaths as of November 25, 2009 along with millions of potential cases. Unlike seasonal influenza, which affects mostly the young and the old, a significant portion of these cases occurred in the middle age group. During one period studied, $87 \%$ of deaths and $71 \%$ of cases of severe pneumonia, a common complication of influenza, occurred in patients aged between 5 and 59. This is in contrast to the average rates of $17 \%$ of deaths and $32 \%$ of cases of severe pneumonia associated with seasonal influenza in this age group [18]. In another study, over half of the case patients were between 13 and 47 years of age [19]. Both of these studies were characterized by severe respiratory disease $[18 ; 19]$. Studies have also shown that there is very little pre-existing immunity towards S-OIV. Specifically, only $1 / 6$ B-cell epitopes in the HA and NA are conserved while T-cell epitopes are much more conserved, 54/78 of CD8+ T-cell epitopes [12]. It should be noted that similar to previous human pandemics, the H1N1 swine flu has no glycosylation on the globular head of it's HA protein, while recent seasonal isolates have these glycosylation sites. The data shown here in the context of an H3N2 virus could have some bearing on the current pandemic. As stated previously, S-OIV has been unusually severe in the middle age group when compared to seasonal isolates. It is possible that some of this is due to T-cell pathology due to glycosylation status as seen in these studies. Only relatively healthy mice showed this Tcell pathology, as in B-cell deficient mice $\mathrm{T}$ cells aid in recovery. It is possible that this is what we are seeing in the middle age group that is generally considered to be not as susceptible to influenza infection. This is not normally an issue as the glycosylation 
status of influenza virus has been increasing and this is seemingly the first time a virus has gone backwards. As each new influenza subtype has emerged in the human population, generally as a pandemic virus, they have all lacked glycosylation on the globular head of the HA protein. As each of these subtypes has evolved in the human population, they have each added glycosylation sites. It seems clear at this point that the addition of N-linked glycosylation sites to the globular head of the influenza HA protein gives the virus some evolutionary advantage. We propose one such advantage here, namely the setup of a situation that allows for a subclinical infection and viral transmission. We believe that this occurs through the blockage of neutralization and neutralizing antibodies by glycosylation.

In the influenza field, much work has been done to optimize the seasonal influenza vaccine. There are many factors that make this particular goal difficult to achieve. One such factor is that of original antigenic sin (OAS)[20-23]. OAS refers to the preferential generation of antibodies against the first antigen seen by the immune system. After a primary infection with one influenza isolate, subsequent infection with a different isolate can lead to the immune response still being directed against the original isolate [24]. Another such factor is the occasional difficulty in generating neutralizing antibodies, which have been shown to be important for subsequent protection [16]. It has been shown previously that glycosylation can shield influenza from neutralizing antibodies [25]. We have seen similar findings in the data shown here. The glycosylation status of the vaccine strain could have some effect on the ability of said vaccine to elicit an effective antibody response. Also if we see reversal of glycosylation status again, as we have seen with S-OIV, vaccination with a glycosylated virus could actually be more harmful than protective. It is also possible that glycosylation plays some role in the lack of cross protection seen in the case of S-OIV and in the case of H5N1, as both of these viruses lack glycosylation on the globular head. Therefore we believe that more research needs to be done on the potential of non-glycosylated vaccines, as they may be more beneficial in protecting the population from future influenza isolates. These findings could have a major impact in vaccine design and be particularly relevant in the context of the current S-OIV pandemic.

\section{Future Directions}

To investigate if the T-cell pathology seen in these studies is dependent on the discussed antibody mismatch and lack of neutralization some extra studies are necessary. To address this concern we will carry out passive antibody transfer studies in B-cell deficient mice [26]. muMT mice lacking B-cells will be infected with +4 virus and challenged with WT virus as previously described. One group of these mice will then be given sera from fully competent mice that were previously infected with +4 , while the other group will be given no sera. As discussed previously, muMT mice infected with +4 virus, then challenged with WT lose weight and eventually succumb to WT challenge, while continuing to have detectable virus in the lungs, whereas immune competent mice succumb to challenge with no detectable virus found in the lungs on day three. We expect to see these same results in the muMT group receiving +4 sera, specifically these 
mice will still succumb to challenge despite lack of detectable virus in the lungs. Lungs from each group of muMT mice can also be stained for CD3+ to determine if the group receiving +4 sera has a greater influx of T cells on WT challenge. Based on previous studies, we expect this will be the case. These studies will help clarify the nature of the observed T-cell pathology in relation to the previously seen lack of neutralization and will help clarify the mechanism of T-cell pathology.

While we have hypothesized that these studies carried out in H3N2 viruses can translate to H1N1 viruses specifically the current swine flu epidemic. While we have shown some data that leads us to believe that these studies are relevant in the context of H1N1 viruses, further research is necessary to support these conclusions. These same experiments can be recapitulated on an $\mathrm{H} 1 \mathrm{~N} 1$ virus. To do this, glycosylation sites will be added to the H1N1 swine flu, which as discussed previously lacks glycosylation on the globular head of its HA. These created viruses can then be used in the same successive infection studies as performed previously. If glycosylation in an $\mathrm{H} 1 \mathrm{~N} 1$ virus has a similar effect on host immune reaction, we would expect to see similar results to the one seen here. This work is currently underway in our laboratory.

As the search for more effective vaccination against influenza continues, another significant question to ask is the impact of glycosylation on vaccine efficacy. As we have seen in an H3N2 virus, the more glycosylation sites a virus has the less of an antibody response it generates in general and specifically towards a lesser glycosylated virus; but what impact will this have in the real world where viruses mutate rapidly? Will glycosylated viruses be more effective against future strains which tend to add glycosylation sites as they evolve or will the increased antibodies generated against relatively non-glycosylated viruses be more valuable? What will happen in the future if we see a reversal of glycosylation similar to that seen in the current swine flu epidemic? Many different studies could be done on this subject. To start to address these questions a series of vaccines could be created containing differing glycosylation. These vaccines could then be used to inoculate mice prior to challenge with different viruses, also containing differing glycosylation. These mice will then be accessed for morbidity, mortality, and antibody response. These studies will allow us to determine the glycosylation status that is most effective against a range of challenge viruses. 


\section{List of References}

[1] Palese P, Shaw ML. Orthomyxoviridae: The viruses and their replication. In: Knipe DM, Howley PM, editors. Fields Virology-Fifth Edition.Philadelphia, PA, Lippincott Williams and Wilkins, 2010: p. 1647-89.

[2] Matrosovich M, Stech J, Klenk HD. Influenza receptors, polymerase and host range. Rev Sci Tech 2009 Apr;28(1):203-17.

[3] Boulo S, Akarsu H, Ruigrok RW, Baudin F. Nuclear traffic of influenza virus proteins and ribonucleoprotein complexes. Virus Res 2007 Mar;124(1-2):12-21.

[4] Smith DJ, Lapedes AS, de Jong JC, et al. Mapping the antigenic and genetic evolution of influenza virus. Science 2004 Jul 16;305(5682):371-6.

[5] Kornfeld R, Kornfeld S. Assembly of asparagine-linked oligosaccharides. Ann Rev Biochem 1985;54:631-4.

[6] Reading PC, Tate MD, Pickett DL, Brooks AG. Glycosylation as a target for recognition of influenza viruses by the innate immune system. Adv Exp Med Biol 2007;598:279-92.

[7] Skehel JJ, Stevens DJ, Daniels RS, et al. A carbohydrate side chain on hemagglutinins of Hong Kong influenza viruses inhibits recognition by a monoclonal antibody. Proc Natl Acad Sci U S A 1984 Mar;81(6):1779-83.

[8] Abe Y, Takashita E, Sugawara K, Matsuzaki Y, Muraki Y, Hongo S. Effect of the addition of oligosaccharides on the biological activities and antigenicity of influenza A/H3N2 virus hemagglutinin. J Virol 2004 Sep;78(18):9605-11.

[9] Vigerust DJ, Ulett KB, Boyd KL, Madsen J, Hawgood S, McCullers JA. N-linked glycosylation attenuates H3N2 influenza viruses. J Virol 2007 Aug;81(16):8593600 .

[10] Hartshorn KL, Webby R, White MR, et al. Role of viral hemagglutinin glycosylation in anti-influenza activities of recombinant surfactant protein D. Respir Res 2008;9:65.

[11] Reading PC, Pickett DL, Tate MD, Whitney PG, Job ER, Brooks AG. Loss of a single $\mathrm{N}$-linked glycan from the hemagglutinin of influenza virus is associated with resistance to collectins and increased virulence in mice. Respir Res 2009;10:117.

[12] Yuste E, Bixby J, Lifson J, Sato S, Johnson W, Desrosiers R. Glycosylation of gp41 of simian immunodeficiency virus shields epitopes that can be targets for neutralizing antibodies. J Virol 2008 Dec;82(24):12472-86. 
[13] Sugimoto C, Nakayama EE, Shioda T, et al. Impact of glycosylation on antigenicity of simian immunodeficiency virus SIV239: induction of rapid V1/V2-specific non-neutralizing antibody and delayed neutralizing antibody following infection with an attenuated deglycosylated mutant. J Gen Virol 2008 Feb;89(Pt 2):554-66.

[14] Li Y, Cleveland B, Klots I, et al. Removal of a single N-linked glycan in human immunodeficiency virus type 1 gp120 results in an enhanced ability to induce neutralizing antibody responses. J Virol 2008 Jan;82(2):638-51.

[15] Srivastava IK, Ulmer JB, Barnett SW. Role of neutralizing antibodies in protective immunity against HIV. Hum Vaccin 2005 Mar;1(2):45-60.

[16] Karlsson Hedestam GB, Fouchier RA, Phogat S, Burton DR, Sodroski J, Wyatt RT. The challenges of eliciting neutralizing antibodies to HIV-1 and to influenza virus. Nat Rev Microbiol 2008 Feb;6(2):143-55.

[17] Okada J, Ohshima N, Kubota-Koketsu R, et al. Monoclonal antibodies in man that neutralized H3N2 influenza viruses were classified into three groups with distinct strain specificity: 1968-1973, 1977-1993 and 1997-2003. Virology $2010 \mathrm{Feb}$ 20;397(2):322-30.

[18] Chowell G, Bertozzi SM, Colchero MA, et al. Severe respiratory disease concurrent with the circulation of H1N1 influenza. N Engl J Med 2009 Aug 13;361(7):674-9.

[19] Perez-Padilla R, de IR-Z, Ponce de LS, et al. Pneumonia and respiratory failure from swine-origin influenza A (H1N1) in Mexico. N Engl J Med 2009 Aug 13;361(7):680-9.

[20] Webster RG, Kasel JA, Couch RB, Laver WG. Influenza virus subunit vaccines. II. Immunogenicity and original antigenic sin in humans. J Infect Dis 1976 Jul;134(1):48-58.

[21] Fazekas de SG, Webster RG. Disquisitions on Original Antigenic Sin. II. Proof in lower creatures. J Exp Med 1966 Sep 1;124(3):347-61.

[22] Fazekas de SG, Webster RG. Disquisitions of Original Antigenic Sin. I. Evidence in man. J Exp Med 1966 Sep 1;124(3):331-45.

[23] Webster RG. Original antigenic sin in ferrets: the response to sequential infections with influenza viruses. J Immunol 1966 Aug;97(2):177-83.

[24] Kim JH, Skountzou I, Compans R, Jacob J. Original antigenic sin responses to influenza viruses. J Immunol 2009 Sep 1;183(5):3294-301. 
[25] Alexander S, Elder JH. Carbohydrate dramatically influences immune reactivity of antisera to viral glycoprotein antigens. Science 1984 Dec 14;226(4680):132830.

[26] Renegar KB, Small PA, Jr. Passive transfer of local immunity to influenza virus infection by IgA antibody. J Immunol 1991 Mar 15;146(6):1972-8. 


\section{Vita}

Keith Calder Wanzeck, born August 12, 1975, received his Bachelor of Science degree in Natural Science with a minor in mathematics at Sienna Heights University, Adrian, MI, in May 2002. He has conducted laboratory research at the University of Michigan Medical School, Ann Arbor, MI; the Nolensville Veterinary Hospital, Nolensville, TN; and St. Jude Children's Research Hospital, Memphis, TN. Keith is a competent and responsible individual who is highly proficient in a vast array of laboratory techniques, safety regulations, and general operation/maintenance. As examples, Keith is experienced in mammalian tissue culture, viral manipulation, and small animal studies, as well as basic biochemistry and immunological assays. He has assisted in general laboratory duties and adherence to safety regulations, while training incoming laboratory members and maintaining effective laboratory operations. 